\title{
Absence Makes the Adaptations Grow Fonder: Proportion of Time Apart From Partner, Male Sexual Psychology, and Sperm Competition in Humans (Homo sapiens)
}

\author{
Todd K. Shackelford, Aaron T. Goetz, William F. McKibbin, and Valerie G. Starratt \\ Florida Atlantic University
}

\begin{abstract}
Sperm competition occurs when the sperm of multiple males concurrently occupy the reproductive tract of a female and compete to fertilize an egg. We used a questionnaire to investigate psychological responses to the risk of sperm competition for 237 men in committed, sexual relationships. As predicted, a man who spends a greater (relative to a man who spends a lesser) proportion of time apart from his partner since the couple's last copulation reported (a) greater sexual interest in his partner, (b) greater distress in response to his partner's sexual rejection, and (c) greater sexual persistence in response to his partner's sexual rejection. All effects were independent of total time since the couple's last copulation and the man's relationship satisfaction. Discussion addresses limitations of the current research and situates the current results within the broader comparative literature on adaptation to sperm competition.
\end{abstract}

Keywords: comparative psychology, sperm competition, human sexuality

Competition between males to fertilize a female's egg(s) can occur before, during, and after copulation (Parker, 1970a, 1970b, 1984; also see Birkhead \& Møller, 1998). When the sperm of two or more males concurrently occupy the reproductive tract of a female and compete to fertilize her egg(s), sperm competition occurs (Parker, 1970a). Sperm competition has been documented or inferred to exist in many species, ranging from molluscs (Baur, 1998), crustaceans (Van Son \& Thiel, 2006), and insects (Simmons, 2001) to birds (Birkhead \& Møller, 1992), reptiles (Rivas \& Burghardt, 2005), and humans (Baker \& Bellis, 1989, 1993; Gallup et al., 2003; Shackelford \& Goetz, in press; Shackelford, Pound, \& Goetz, 2005; Smith, 1984; Starratt, Shackelford, Goetz, \& McKibbin, in press). Avian sperm competition research is particularly interesting for students of human mating because humans and many avian species share similar mating systems, adaptive problems, and adaptive solutions (Shackelford \& Goetz, 2006).

Most avian species practice social monogamy (Birkhead \& Møller, 1992), a mating system in which males and females form long-term pair bonds but also pursue extra-pair copulations. Males gain access to the reproductive value of females, whereas females gain access to the paternal investment of males. This exchange of reproductive resources is rarely exclusive in socially monogamous species, however. Genetic analyses document that social monogamy in birds does not necessarily indicate sexual and genetic monogamy (e.g., Burke, Davies, Bruford, \& Hatchwell, 1989). Female extra-pair copulation in socially monogamous birds is widely documented and is the primary context for sperm competition (Birkhead \& Møller, 1992).

Todd K. Shackelford, Aaron T. Goetz, William F. McKibbin, and Valerie G. Starratt, Department of Psychology, Florida Atlantic University.

Correspondence concerning this article should be addressed to Todd K. Shackelford, Department of Psychology, Florida Atlantic University, 2912 College Avenue, Davie, FL 33314. E-mail: tshackel@fau.edu
The socially monogamous avian mating system - and the female extra-pair copulation that is the primary context for sperm competition-also is characteristic of humans. Humans are socially monogamous, with both sexes engaging in extra-pair copulation under predictable conditions (Baker \& Bellis, 1989, 1995; Buss, 2003; Gangestad, Thornhill, \& Garver-Apgar, 2005a). Smith (1984) provided empirical and theoretical arguments that female extra-pair copulation is the primary context for sperm competition in humans (also see Baker \& Bellis, 1989, 1993, 1995; Shackelford \& Goetz, in press; Shackelford et al., 2005; Starratt et al., in press).

Female extra-pair copulation generates the adaptive problem of sperm competition for the men to whom women are pair-bonded. One way to solve the adaptive problem of partner extra-pair copulation is for a man to inseminate into his partner more sperm when sperm competition risk is greater or more likely. Male humans appear to have evolved mechanisms for anticipating risk of partner extra-pair copulation and associated sperm competition. Baker and Bellis $(1989,1993)$ documented empirically that men may be physiologically designed to respond adaptively to sperm competition risk. Consistent with sperm competition theory, Baker and Bellis (1989, 1993, 1995) documented a large positive correlation between sperm competition risk and the number of sperm a man inseminates into his partner at the couple's next copulation.

Baker and Bellis (1989, 1993, 1995) investigated physiological adjustments to sperm competition risk. There must also be psychological mechanisms (or information processing devices) linked to these adjustments, just as human penile erection (a physiological response) is typically accompanied by sexual arousal (a psychological response). Human male psychology appears to include mechanisms that motivate behavior that would have increased the probability of success in sperm competition for ancestral men. Psychological mechanisms designed to combat sperm competition appear to be activated when men perceive that partner extra-pair copulation may have occurred. Shackelford et al. (2002) provided the first empirical evidence of male psychological adaptation to 
sperm competition in humans: With a greater proportion of time spent apart from their partner since the couple's last copulation (and, therefore, greater risk of sperm competition), men reported (a) their partner to be more attractive, (b) greater interest in copulating with their partner, (c) that other men found their partner more attractive, and (d) that their partner was more sexually interested in them. These results were independent of both total time since the couple's last copulation and men's relationship satisfaction. These perceptual changes may motivate men to copulate as soon as possible with their partner, thereby entering their sperm into competition with any rival sperm that may be present in her reproductive tract.

Shackelford et al. (2002) also predicted that proportion of time spent apart would correlate positively with distress following a partner's denial of his request for copulation with her. This prediction, however, was not supported statistically. In the current research, we present a new test of the prediction that the proportion of time spent apart predicts distress following denial of a request for copulation. In addition, we assess men's sexual persistence following a partner's denial of a request for copulation, and we test the prediction that distress following the denial of a request for copulation will motivate men to be more persistent in requests for copulation.

Following Shackelford et al. (2002; also see Baker \& Bellis, 1989, 1993, 1995; Starratt et al., in press), we operationalized sperm competition risk as the proportion of time that a couple has spent apart since their last copulation. The proportion of time that a couple has spent apart since their last copulation may be information processed by psychological mechanisms that subsequently motivate a man to inseminate his partner as soon as possible, to combat the increased sperm competition risk.

Total time since last copulation is not linked to sperm competition risk (Shackelford et al., 2002). It is the proportion of time that a couple has spent apart since their last copulation that is linked to sperm competition risk (Shackelford et al., 2002; also see Baker \& Bellis, 1989, 1993, 1995; Starratt et al., in press). As total time since last copulation increases, a man might feel increasingly sexually frustrated and increasingly interested in copulation with his partner, independent of the proportion of time he and his partner have spent apart since their last copulation. To address this potential confound, we assessed the relationships between male sexual psychology (i.e., psychological mechanisms that motivate sexual affect and cognition; see Shackelford et al., 2002; and for review, see Platek \& Shackelford, 2006) and behaviors predicted to be linked to sperm competition risk (as assessed by the proportion of time spent apart since the couple's last copulation), independent of the total time since a couple's last copulation.

Relationship satisfaction may influence the relationship between the proportion of time a couple has spent apart since their last copulation and male sexual psychology. A man's satisfaction with the relationship might be related to his reported sexual interest in his partner. Unlike a greater proportion of time spent apart since the couple's last copulation, a man's relationship satisfaction is not clearly linked to sperm competition risk. We addressed this potential confound by investigating the relationships between male sexual psychology and behaviors predicted to be linked to sperm competition risk (as assessed by the proportion of time spent apart since the couple's last copulation), independent of a man's relationship satisfaction.
In summary, the current research tested the hypothesis that human male psychology includes mechanisms designed to attend to the risk of sperm competition as assessed by the proportion of time that a couple has spent apart since their last copulation, independent of (a) the total time since the couple's last copulation and (b) the man's relationship satisfaction. A key component of this hypothesis is that the output of these mechanisms includes increased motivation to copulate with one's partner. We generated three predictions from this hypothesis. A man's self-reported sexual interest in his partner presumably predicts his active pursuit of copulation with his partner. This leads to the first prediction:

Prediction 1. A man who spends a greater (relative to a man who spends a lesser) proportion of time apart from his partner since the couple's last copulation will report greater sexual interest in his partner, independent of (a) the total time since the couple's last copulation and (b) the man's relationship satisfaction.

According to strategic interference theory (Buss, 1989; also see Buss, 2003), negative emotions-such as anger, frustration, and being upset-signal interference with a strategy that was reproductively successful for our ancestors. These negative emotions call attention to the strategic interference and motivate removal of the interference. The intensity of the negative emotions corresponds to the intensity of strategic interference. A woman's denial of her partner's request for copulation is expected to generate distress in her partner that corresponds to the current sperm competition risk he faces, which is indexed by the proportion of time that the couple has spent apart since their last copulation. This leads to the second prediction:

Prediction 2. A man who spends a greater (relative to a man who spends a lesser) proportion of time apart from his partner since the couple's last copulation will report greater distress following his partner's denial of a request for copulation, independent of (a) the total time since the couple's last copulation and (b) the man's relationship satisfaction.

A woman's denial of her partner's request for copulation is predicted to cause distress in her partner. This distress might, first, call her partner's attention to the strategic interference and, second, motivate him to remove the source of interference-in this case, to negotiate when the next copulation will occur. This leads to the third prediction:

Prediction 3. A man who spends a greater (relative to a man who spends a lesser) proportion of time apart from his partner since the couple's last copulation will report greater sexual persistence following his partner's denial of a request for copulation, independent of (a) the total time since the couple's last copulation and (b) the man's relationship satisfaction.

To test these predictions, we collected self-report data from men in committed, sexual relationships.

\section{Method}

\section{Participants}

Participants were 237 men drawn from universities and surrounding communities and currently in a committed, sexual, het- 
erosexual relationship. The mean age of participants was 25.6 years $(S D=8.1)$, and the mean age of participants' partners was 24.4 years $(S D=7.4)$. The mean duration of participants' current relationship was 49.6 months $(S D=63.0)$. Table 1 presents additional descriptive statistics.

\section{Materials}

Each participant completed a brief self-report survey. Each participant was instructed to answer the questions honestly and was reminded that his responses were anonymous. The first section of the survey collected demographic information, including the participant's age, his partner's age, and the duration of their relationship. The second section of the survey addressed the key sexuality variables. First, each participant was asked how many hours had passed since he last had sexual intercourse with his partner. Next, each participant was asked how many hours he had spent together with his partner, including sleeping time, since he last had sexual intercourse with his partner (following Baker \& Bellis, 1989, 1993, 1995; Shackelford et al., 2002; Starratt et al., in press).

Following Shackelford et al. (2002), the next set of questions asked each participant to think about his feelings "at this moment in time" and to rate the following items on 10-point Likert scales ranging from 0 (much less than usual) to 9 (much more than usual): How interested is the participant in having sex with his partner? How physically attractive does the participant think his partner is? How sexually attractive does the participant think his partner is? How sexually attracted to the participant is the participant's partner?

Also following Shackelford et al. (2002), the third section of the survey asked each participant to answer questions about how he would feel "at that moment in time" if his partner denied a request to have sexual intercourse with him. Each participant was asked to rate his resulting anger, frustration, upset feelings, and persistence on a 10-point Likert scale ranging from 0 (not at all) to 9 (extremely). Each participant also was asked to indicate whether his interest in having sexual intercourse with his partner would change if she denied his request to have sexual intercourse with him on a 10-point Likert scale ranging from 0 (I would be much less interested in sex with my partner) to 9 (I would be much more interested in sex with my partner). The fourth section of the survey (following Shackelford et al., 2002; also following Shackelford \& Buss, 2000) asked each participant to rate his commitment to his partner and his overall, sexual, and emotional satisfaction with his

Table 1

Descriptive Statistics for Target Variables

\begin{tabular}{lrr}
\hline \multicolumn{1}{c}{ Variable } & \multicolumn{1}{c}{$M$} & \multicolumn{1}{c}{$S D$} \\
\hline Proportion of time apart since last copulation & 0.6 & 0.3 \\
Total time since last copulation (hours) & 55.9 & 42.3 \\
Relationship satisfaction $^{\mathrm{a}}$ & 7.6 & 1.4 \\
Sexual interest in partner $^{\mathrm{a}}$ & 6.9 & 1.4 \\
Distress following partner's sexual rejection $^{\mathrm{a}}$ & 3.8 & 2.3 \\
Persistence following partner's sexual rejection $^{\mathrm{a}}$ & 4.2 & 2.0 \\
\hline
\end{tabular}

Note. $\quad N=237$.

${ }^{\text {a }}$ Variable is a composite (see text), with scale anchored by $0=$ low value on variable and $9=$ high value on variable. partner. These ratings were provided on 10-point Likert scales ranging from 0 (not at all) to 9 (extremely).

\section{Procedure}

Upon arriving at the scheduled location, participants were handed a consent form and survey. The participants were instructed to read and sign the consent form, complete the survey, and then place the survey into an envelope, which they then sealed. Participants were asked to place the signed consent form in a separate envelope to maintain anonymity.

\section{Results}

The proportion of time the couple had spent apart since their last copulation was calculated by subtracting the number of hours that the couple had spent together since their last copulation from the total number of hours since the couple's last copulation and dividing this difference by the total number of hours since the couple's last copulation (following Shackelford et al., 2002; also following Baker \& Bellis, 1989, 1993, 1995; Starratt et al., in press). Relationship satisfaction $(\alpha=.87)$ is the mean of responses to four items: (a) participant's overall satisfaction with his partner, (b) participant's sexual satisfaction with his partner, (c) participant's emotional satisfaction with his partner, and (d) participant's commitment to his partner (following Shackelford et al., 2002; also following Shackelford \& Buss, 2000). Participant's sexual interest in partner $(\alpha=.80)$ is the mean of responses to four items: (a) participant's interest in sex with his partner, (b) participant's assessment of his partner's sexual attractiveness, (c) participant's assessment of his partner's physical attractiveness, and (d) participant's assessment of his partner's sexual attraction to the participant (following Shackelford et al., 2002). Distress following partner's denial of a request for copulation $(\alpha=.89)$ is the mean of responses to three items: (a) anger following his partner's denial of his request for copulation, (b) frustration following his partner's denial of his request for copulation, and (c) upset feelings following his partner's denial of his request for copulation (following Shackelford et al., 2002). Persistence following his partner's denial of his request for copulation $(\alpha=.55)$ is the mean of responses to two items: (a) persistence in having sex with his partner following his partner's denial of a request for copulation and (b) change in interest in sex with his partner following his partner's denial of a request for copulation. Table 1 presents descriptive statistics for the key variables.

Following the analytic strategy of Shackelford et al. (2002), we tested each of the three predictions with multiple regression. For each prediction, three predictors were entered into a regression equation predicting a single dependent variable. These three predictors were (a) the proportion of time the couple spent apart since their last copulation, (b) the total time since the couple's last copulation, and (c) the participant's relationship satisfaction. Each prediction states that the proportion of time spent apart since the couple's last copulation will predict the target dependent variable, independent of the total time since the couple's last copulation and independent of the participant's relationship satisfaction.

Table 2 presents the results of the three multiple regressions conducted to test the three predictions. The table presents, for each multiple regression, the standardized regression coefficient and the 
Table 2

Results of Multiple Regressions of Proportion of Time Spent Apart Since Last Copulation, Total Time Since Last Copulation, and Relationship Satisfaction on Dependent Variables

Predictor variable

\begin{tabular}{|c|c|c|c|c|c|c|c|c|c|}
\hline \multirow[b]{2}{*}{ Dependent variable } & \multicolumn{3}{|c|}{$\begin{array}{l}\text { Proportion of time spent } \\
\text { apart since last copulation }\end{array}$} & \multicolumn{3}{|c|}{ Total time since last copulation } & \multicolumn{3}{|c|}{ Relationship satisfaction } \\
\hline & $B$ & $t(236)$ & $d$ & $B$ & $t(236)$ & $d$ & $B$ & $t(236)$ & $d$ \\
\hline $\begin{array}{l}\text { Sexual interest in partner (Prediction 1) } \\
\text { Distress following partner's sexual }\end{array}$ & 0.17 & $2.88^{* *}$ & 0.38 & -0.05 & -0.84 & -0.11 & 0.57 & $10.42^{* * *}$ & 1.36 \\
\hline rejection (Prediction 2) & 0.14 & $2.01^{*}$ & 0.26 & -0.07 & -1.06 & -0.14 & -0.12 & -1.79 & -0.23 \\
\hline $\begin{array}{l}\text { Persistence following partner's sexual } \\
\text { rejection (Prediction 3) }\end{array}$ & 0.23 & $3.31^{* * * *}$ & 0.43 & -0.13 & $-1.98^{*}$ & -0.26 & 0.04 & 0.63 & 0.08 \\
\hline
\end{tabular}

Note. $\quad N=237 . B$ is the standardized regression coefficient, $t$ is the value associated with the test of the significance of the $B$, and $d$ is the associated effect size index (Cohen, 1988, defines an effect size as small if $d=|0.20|$, medium if $d=|0.50|$, and large if $d=|0.80|$ or greater).

${ }^{*} p<.05{ }^{* *} p<.01{ }^{* * * *} p<.001$.

associated $t$ value and effect size index $d$ (Cohen, 1988) for each of the three predictors. The first row of Table 2 shows that the greater the proportion of time that a couple has spent apart since their last copulation, the more sexually interested a man is in his partner, independent of the total time since the couple's last copulation and independent of the man's relationship satisfaction, $F(3,232)=36.60, p<.001, n^{2}=.324$. Effect size index $n^{2}$ is interpreted as the proportion of variance in the predicted variable accounted for by the predictor variables. Cohen (1988) defines $n^{2}$ as small if $n^{2}=.0099$, medium if $n^{2}=.0588$, and large if $n^{2}=$ .1379 or greater. Prediction 1 therefore was supported. Total time since the couple's last copulation did not independently predict a man's sexual interest in his partner. Relationship satisfaction positively predicted a man's sexual interest in his partner.

The second row of Table 2 shows that the greater the proportion of time that a couple has spent apart since their last copulation, the more distress a man reports in response to his partner's denial of his request for copulation, independent of the total time since the couple's last copulation and independent of the man's relationship satisfaction, $F(3,232)=2.96, p<.05, n^{2}=.037$. Prediction 2 therefore was supported. Neither total time since last copulation nor relationship satisfaction independently predicted a man's distress in response to his partner's sexual rejection.

The third row of Table 2 shows that the greater the proportion of time that a couple has spent apart since their last copulation, the more sexual persistence a man reports in response to his partner's denial of his request for copulation, independent of the total time since last copulation and independent of the man's relationship satisfaction, $F(3,232)=3.98, p<.01, n^{2}=.050$. Prediction 3 therefore was supported. Total time since the couple's last copulation negatively predicted sexual persistence in response to a partner's sexual rejection. Relationship satisfaction did not independently predict sexual persistence. The sexual persistence composite variable included just two items (see above), and this may account for the relatively low reliability for this variable. The correlation between responses to the two items $(r=.38)$ provides empirical evidence for overlap in the variance accounted for by the two items. Separate multiple regressions on the two items generated results identical in pattern to the multiple regressions on the composite variable (analyses available on request). Rather than present and discuss the results of these separate multiple regressions using single-item assessments of unknown reliability, we present and discuss the results of a single multiple regression using the composite variable of less than optimal but known reliability.

\section{Discussion}

This research tested the hypothesis that male humans have psychological adaptations to sperm competition. Over evolutionary history, female humans at least occasionally mated with multiple men within a sufficiently short time frame and thereby generated sperm competition (Baker \& Bellis, 1989, 1993, 1995; Platek \& Shackelford, 2006; Shackelford \& Goetz, 2006; in press; Shackelford \& Pound, 2006; Shackelford et al., 2005; Smith, 1984; Starratt et al., in press). A man equipped with psychological mechanisms that motivated him to inseminate his partner as soon as possible following his partner's extra-pair copulation would have out-reproduced a male that lacked the requisite mechanisms and therefore took no such corrective action. Shackelford et al. (2002) first documented empirically that men may have psychological mechanisms designed to address adaptive problems of sperm competition. The present research provides further empirical evidence that male psychology may include mechanisms designed to address adaptive problems of sperm competition.

Following Shackelford et al. (2002; also following Baker \& Bellis, 1989, 1993, 1995; Starratt et al., in press), we operationalized the risk of sperm competition as the proportion of time a couple has spent apart since their last copulation. When a couple is apart, a man cannot know for certain his partner's activities. The time a woman spends apart from her partner is time potentially spent copulating with another man. A woman, therefore, is increasingly likely to be inseminated by another man with an increasing proportion of time spent apart from her partner since the couple's last copulation (Baker \& Bellis, 1989, 1993, 1995; Shackelford et al., 2002; Starratt et al., in press). We tested and found empirical support for three predictions derived from the hypothesis that male psychology includes mechanisms designed to attend to the proportion of time a couple has spent apart since their last copulation as an indicator of the risk of sperm competition. Replicating the results of Shackelford et al. (2002), we found that a man who 
spends a greater (relative to a man who spends a lesser) proportion of time apart from his partner since the couple's last copulation reports greater interest in copulating with his partner. We extend previous research by documenting that a man who spends a greater (relative to a man who spends a lesser) proportion of time apart from his partner since the couple's last copulation also reports greater distress and greater sexual persistence following his partner's denial of a request for copulation.

These effects of the proportion of time spent apart since the couple's last copulation are statistically independent of the total number of hours since the couple's last copulation. Therefore, it is not that these men are simply sexually frustrated. Total time since the couple's last copulation has no independent predictive effect on two of the three dependent variables that we examined. Total time since the couple's last copulation negatively predicted men's persistence following sexual rejection by their partner. Perhaps men who report greater persistence following copulatory denial would consequently tend to experience shorter total time between in-pair copulations. The effects of the proportion of time spent apart since the couple's last copulation also are statistically independent of the man's relationship satisfaction. Regardless of his satisfaction with the relationship, a man who has spent a greater proportion of time apart from his partner since the couple's last copulation appears to be motivated to inseminate his partner sooner than a man who has spent a greater proportion of time together with his partner since the couple's last copulation. Consistent with previous research (Shackelford et al., 2002; also see Buss, 2003, for a review), a man's relationship satisfaction does independently predict his sexual interest in his partner.

The results of the current research are consistent with the results of previous research investigating adaptation to sperm competition in humans, notably Shackelford et al. (2002) and Gallup et al. (2003). Gallup and his colleagues, for example, predicted and documented relationships between a man's suspicions of his partner's sexual infidelities, physical separation from his partner, and a man's copulatory behaviors upon physical reunion with his partner (e.g., engaging in deeper copulatory thrusting following physical separation). Whereas in the current research (and in Shackelford et al., 2002; Starratt et al., in press; also in Baker \& Bellis, 1989, 1993, 1995), risk of sperm competition was assessed as the proportion of time spent apart since the couple's last copulation, Gallup et al. investigated copulatory behaviors after a period of physical separation (as an assay of sperm competition risk) but did not assess the total time since last in-pair copulation or the time spent apart since last in-pair copulation. Gallup et al.'s methodology, therefore, does not allow one to eliminate the alternative, sexual frustration interpretation of the results discussed above.

Despite these and other methodological differences between the current research and previous research investigating adaptations to human sperm competition (reviewed in Shackelford et al., 2005), a coherent set of results is beginning to emerge. The current research adds to a rapidly growing literature indicating that sperm competition is likely to have been a recurrent adaptive problem confronted by ancestral men and that this adaptive problem led to the evolution of adaptive solutions to sperm competition (e.g., Baker \& Bellis, 1993; Gallup, Burch, \& Berens Mitchell, 2006; Gallup et al., 2003; Goetz \& Shackelford, 2006; Goetz et al., 2005; Kilgallon \& Simmons, 2005; Klusmann, 2002, 2006; Platek \&
Shackelford, 2006; Pound, 2002; Shackelford, Goetz, Guta, \& Schmitt, 2006; Shackelford et al., 2002; Shackelford \& Pound, 2006; Shackelford et al., 2005; Smith, 1984; Starratt et al., in press; Wyckoff, Wang, \& Wu, 2000).

The current research has several limitations. One is a sample limitation. The mechanisms that may have evolved in response to the adaptive problems of sperm competition are proposed to be universally present in male psychology. The current sample included mostly young men at or around a university in a large metropolitan area. Future research must sample men from different socioeconomic, age, educational, ethnic, and cultural groups. If similar results are documented in diverse samples, this would provide evidence of the universality of male psychological adaptations to sperm competition.

A second limitation of the current research is a design limitation. We secured single assessments of feelings and desires that were predicted to covary with the proportion of time spent apart since the couple's last copulation. The nature of this design precludes a causal analysis of the relationships between sperm competition risk and the psychological reactions to sperm competition risk. It would be valuable to assess these relationships over an extended period of time, such as in a 1-month daily diary study. A daily diary study of couples in a committed sexual relationship would allow for a causal analysis of predicted relationships, such as the relationship between the proportion of time that the couple has spent apart since their last copulation and a man's interest in copulating with his partner.

A third potential limitation is a methodological limitation. We secured assessments of men's distress and sexual persistence following their partner's hypothetical denial of a request for copulation. A better test of this prediction may require that a participant report his distress and sexual persistence following his partner's most recent denial of a request for copulation since the couple's last copulation. Distress following a partner's actual denial of a request for copulation then could be regressed on the proportion of time spent apart since the couple's last copulation, total time since the couple's last copulation, and the man's relationship satisfaction. This analysis strategy may have problems, however. The analysis would need to be restricted to men whose partners had denied them copulation in the interim since the last in-pair copulation. There might be factors unknown to the researcher that differentiate a man who does and a man who does not report that his partner has denied him sexual access.

The current research can be extended in several different directions. Although we found that a man who spends a greater (relative to a man who spends a lesser) proportion of time apart from his partner since the couple's last copulation reported greater partnerdirected copulatory interest, this relationship could be moderated by men's perceptions of their partners' likelihood of infidelity, independent of time spent apart from their partner since the couple's last copulation. For example, some women-such as those mated to men with high developmental instability (e.g., high fluctuating asymmetry) - may be more likely to engage in extrapair copulations (Gangestad, Thornhill, \& Garver-Apgar, 2005b). We might, therefore, predict that the relationship between the proportion of time spent apart from partner since the couple's last copulation and men's partner-directed copulatory interest would be greater in men with high fluctuating asymmetry than in men with low fluctuating asymmetry. 
Future research also might investigate other variables potentially affected by partner absence. For example, a man who spends a greater (relative to a man who spends a lesser) proportion of time apart from his partner since the couple's last copulation might report, if rejected sexually, the use of sexual coercion at the couple's next copulation. This hypothesis is in line with recent research suggesting that sexual coercion in the context of an intimate relationship may function as a sperm competition tactic (e.g., Goetz \& Shackelford, 2006).

The current findings also have implications for other nonhuman species. Behavioral data, for example, can be collected to examine the relationship between sexual persistence and sperm competition risk. Attempted mounts, for example, could be measured following partner absence. Moreover, stress hormones could be assayed in males who have been returned to female partners who are not interested in mating. Rats (e.g., Rattus norvegicus) might make an appropriate model for such tests as it has been demonstrated that rats adjust the number of sperm they inseminate according to the amount of time they have spent guarding a particular female (Bellis, Baker, \& Gage, 1990) and according to the presence of a rival male (Pound \& Gage, 2004).

In conclusion, a large body of research has documented the existence and adaptive functioning of mechanisms apparently designed to solve the adaptive problems of sperm competition in many different animals. The current research provides new empirical evidence that human male psychology also may include mechanisms designed to solve the adaptive problems of sperm competition. We are not aware of a theory other than sperm competition theory that can account for the predictive utility of the proportion of time spent apart since the couple's last copulation, independent of the total time since the couple's last copulation and independent of men's relationship satisfaction. The current research adds to a growing literature indicating that male humans, like the males of other socially monogamous species, may have psychological mechanisms that are designed to address adaptive problems of sperm competition.

\section{References}

Baker, R. R., \& Bellis, M. A. (1989). Number of sperm in human ejaculates varies in accordance with sperm competition theory. Animal Behaviour, 37, 867-869.

Baker, R. R., \& Bellis, M. A. (1993). Human sperm competition: Ejaculate adjustment by males and the function of masturbation. Animal Behaviour, 46, 861-885.

Baker, R. R., \& Bellis, M. A. (1995). Human sperm competition. London: Chapman \& Hall.

Baur, B. (1998). Sperm competition in molluscs. In T. R. Birkhead \& A. P. Møller (Eds.), Sperm competition and sexual selection (pp. 255-305). San Diego, CA: Academic Press.

Bellis, M. A., Baker, R. R., \& Gage, M. J. G. (1990). Variation in rat ejaculates consistent with the Kamikaze sperm hypothesis. Journal of Mammalogy, 71, 479-480.

Birkhead, T. R., \& Møller, A. P. (1992). Sperm competition in birds. London: Academic Press.

Birkhead, T. R., \& Møller, A. P. (Eds.). (1998). Sperm competition and sexual selection. San Diego, CA: Academic Press.

Burke, T., Davies, N. B., Bruford, M. W., \& Hatchwell, B. J. (1989, March 16). Parental care and mating behaviour of polyandrous dunnocks, Prunella modularis, related to paternity by DNA fingerprinting. Nature, 338, 249-251.
Buss, D. M. (1989). Conflict between the sexes: Strategic interference and the evocation of anger and upset. Journal of Personality and Social Psychology, 56, 735-747.

Buss, D. M. (2003). The evolution of desire (Rev. ed.). New York: Basic Books.

Cohen, J. (1988). Statistical power analysis for the behavioral sciences (2nd ed.). Hillsdale, NJ: Erlbaum.

Gallup, G. G., Burch, R. L., \& Berens Mitchell, T. J. (2006). Semen displacement as a sperm competition strategy: Multiple mating, selfsemen displacement, and timing of in-pair copulations. Human Nature, $17,253-264$.

Gallup, G. G., Burch, R. L., Zappieri, M. L., Parvez, R. A., Stockwell, M. L., \& Davis, J. A. (2003). The human penis as a semen displacement device. Evolution and Human Behavior, 24, 277-289.

Gangestad, S. W., Thornhill, R., \& Garver-Apgar, C. E. (2005a). Adaptations to ovulation: Implications for sexual and social behavior. Current Directions in Psychological Science, 14, 312-316.

Gangestad, S. W., Thornhill, R., \& Garver-Apgar, C. E. (2005b). Women's sexual interests across the ovulatory cycle depend on primary partner developmental instability. Proceedings of the Royal Society of London, B, 272, 2023-2027.

Goetz, A. T., \& Shackelford, T. K. (2006). Sexual coercion and forced in-pair copulation as sperm competition tactics in humans. Human Nature, 17, 265-282.

Goetz, A. T., Shackelford, T. K., Weekes-Shackelford, V. A., Euler, H. A., Hoier, S., Schmitt, D. P., \& LaMunyon, C. W. (2005). Mate retention, semen displacement, and human sperm competition: A preliminary investigation of tactics to prevent and correct female infidelity. Personality and Individual Differences, 38, 749-763.

Kilgallon, S. J., \& Simmons, L. W. (2005). Image content influences men's semen quality. Biology Letters, 1, 253-255.

Klusmann, D. (2002). Sexual motivation and the duration of partnership. Archives of Sexual Behavior, 31, 275-287.

Klusmann, D. (2006). Sperm competition and female procurement of male resources as explanations for a sex-specific time course in the sexual motivation of couples. Human Nature, 17, 283-300.

Parker, G. A. (1970a). The reproductive behaviour and the nature of sexual selection in Scatophaga stercoraria: V. The female's behaviour at the oviposition site. Behaviour, 37, 140-168.

Parker, G. A. (1970b). Sperm competition and its evolutionary consequences in the insects. Biological Reviews, 45, 525-567.

Parker, G. A. (1984). Sperm competition and the evolution of animal mating strategies. In R. L. Smith (Ed.), Sperm competition and the evolution of animal mating systems (pp. 1-60). London: Academic Press.

Platek, S. M., \& Shackelford, T. K. (Eds.). (2006). Female infidelity and paternal uncertainty. New York: Cambridge University Press.

Pound, N. (2002). Male interest in visual cues of sperm competition risk. Evolution and Human Behavior, 23, 443-466.

Pound, N., \& Gage, M. J. G. (2004). Prudent sperm allocation in Rattus norvegicus: A mammalian model of adaptive ejaculate adjustment. Animal Behaviour, 68, 819-823.

Rivas, J. A., \& Burghardt, G. M. (2005). Snake mating systems, behavior, and evolution: The revisionary implications of recent findings. Journal of Comparative Psychology, 119, 447-454.

Shackelford, T. K., \& Buss, D. M. (2000). Marital satisfaction and spousal cost-infliction. Personality and Individual Differences, 28, 917-928.

Shackelford, T. K., \& Goetz, A. T. (2006). Comparative psychology of sperm competition. Journal of Comparative Psychology, 120, 139-146.

Shackelford, T. K., \& Goetz, A. T. (in press). Adaptation to sperm competition in humans. Current Directions in Psychological Science.

Shackelford, T. K., Goetz, A. T., Guta, F. E., \& Schmitt, D. P. (2006). Mate guarding and frequent in-pair copulation in humans: Concurrent or compensatory anti-cuckoldry tactics? Human Nature, 17, 239-252. 
Shackelford, T. K., LeBlanc, G. J., Weekes-Shackelford, V. A., BleskeRechek, A. L., Euler, H. A., \& Hoier, S. (2002). Psychological adaptation to sperm competition. Evolution and Human Behavior, 23, 123138.

Shackelford, T. K., \& Pound, N. (Eds.). (2006). Sperm competition in humans. New York: Springer.

Shackelford, T. K., Pound, N., \& Goetz, A. T. (2005). Psychological and physiological adaptations to sperm competition in humans. Review of General Psychology, 9, 228-248.

Simmons, L. W. (2001). Sperm competition and its evolutionary consequences in the insects. Princeton, NJ: Princeton University Press.

Smith, R. L. (1984). Human sperm competition. In R. L. Smith (Ed.), Sperm competition and the evolution of animal mating systems (pp. 601-660). New York: Academic Press.
Starratt, V. G., Shackelford, T. K., Goetz, A. T., \& McKibbin, W. F. (in press). Male mate retention behaviors vary with risk female infidelity and sperm competition. Acta Psychologica Sinica.

Van Son, T. C., \& Thiel, M. (2006). Mating behaviour of male rock shrimp, Rhynchocinetes typus (Decapoda: Caridea): Effect of recent mating history and predation risk. Animal Behaviour, 71, 61-70.

Wyckoff, G. J., Wang, W., \& Wu, C. (2000, January 20). Rapid evolution of male reproductive genes in the descent of man. Nature, 403, 304-308.

Received May 18, 2006

Revision received November 22, 2006 Accepted November 22, 2006

\section{American Psychological Association SUbSCRIPTION Claims Information}

Today's Date:

We provide this form to assist members, institutions, and nonmember individuals with any subscription problems. With the appropriate information we can begin a resolution. If you use the services of an agent, please do NOT duplicate claims through them and directly to us. PLEASE PRINT CLEARLY AND IN INK IF POSSIBLE.

\begin{tabular}{llll}
\hline PRINT FULL NAME OR KEY NAME OF NNSTITUTION & & \\
\hline ADDRESS & & & \\
\hline CITY & & & \\
\hline
\end{tabular}

YOUR NAME AND PHONE NUMBER

TITLE

\section{MEMBER OR CUSTOMER NUMBER (MAY BEFOUND ON ANY PAST ISSUE LABEL)} DATE YOUR ORDER WAS MAILED (OR PHONED)

PREPAID

\section{CHECK _CHARGE}

CHECK/CARD CLEARED DATE:

(If possible, send a copy, front and back, of your cancelled check to help us in our research of your clainn.)

ISSUES: __ MISSLNG _ DAMAGED

Thank you. Once a claim is received and resolved, delivery of replacement issues routinely takes 4-6 weeks.

(TO BE FILLED OU'T BY APA STAFF)

DATE RECEIVED:

ACTION TAKEN:

STAFF NAME:
DATE OF ACTION:

INV. NO. \& DATE:

LABEL NO. \& DATE:

Send this form to APA Subscription Claims, 750 First Street, NE, Washington, DC 20002-4242

PLEASE DO NOT REMOVE. A PHOTOCOPY MAY BE USED. 